OPEN ACCESS

Edited by:

Brian Dixon,

University of Waterloo, Canada

Reviewed by:

Katherine Buckley,

Carnegie Mellon University,

United States

Stephanie DeWitte-Orr,

Wilfrid Laurier University, Canada

*Correspondence:

Zuobing Zhang

zbzhang@sxu.edu.cn

Heng Chi

chiheng@qdio.ac.cn

heng.chi@uit.no

Roy A. Dalmo

roy.dalmo@uit.no

Specialty section

This article was submitted to

Comparative Immunology,

a section of the journal

Frontiers in Immunology

Received: 09 November 2018

Accepted: 09 January 2019

Published: 25 January 2019

Citation:

Zhang Z, Chi H and Dalmo RA (2019)

Trained Innate Immunity of Fish Is a

Viable Approach in Larval

Aquaculture. Front. Immunol. 10:42.

doi: 10.3389/fimmu.2019.00042

\section{Trained Innate Immunity of Fish Is a Viable Approach in Larval Aquaculture}

\author{
Zuobing Zhang ${ }^{1 *}$, Heng Chi ${ }^{2,3 *}$ and Roy A. Dalmo ${ }^{3 *}$ \\ ${ }^{1}$ School of Life Science, Shanxi University, Taiyuan, China, ${ }^{2}$ Key Laboratory of Experimental Marine Biology, Institute of \\ Oceanology, Chinese Academy of Sciences, Qingdao, China, ${ }^{3}$ Research Group Aquaculture and Environment, Norwegian \\ College of Fishery Science, Faculty of Biosciences, Fisheries and Economy, University of Tromsø-The Arctic University of \\ Norway, Tromsø, Norway
}

The general understanding has been that only adaptive immunity is capable of immunological memory, but this concept has been challenged in recent years by studies showing that innate immune systems can mount resistance to reinfection-as the innate immune system can adapt its function following an insult. Innate immune training offers an attractive approach in intensive fish larval rearing, especially since the adaptive immune system is not fully developed. Trained innate immunity will potentially favor robust fish in terms of resistance to viral and bacterial diseases. So-called immunostimulants such as B-glucans have for decades been used both in laboratories and in intensive fish aquaculture. Treatment of fish by B-glucans (and by other substances with pathogen-associated molecular patterns) often induces activation of non-specific/innate immune mechanisms and induces higher disease resistance. The reported effects of e.g., B-glucans fit nicely into the concept "trained innate immunity," but the research on fish does not yet include analysis of epigenetic changes that may be a prerequisite for long-lasting trained innate immunity. In this "perspective," we will discuss how in practical terms and based on prior knowledge one can introduce innate immune training in brood stock fish, and their offspring, and whether innate immune training by B-glucans is a viable approach in larval aquaculture.

\section{Keywords: trained innate immunity, aquaculture, fish, beta-glucan, fish larvae}

\section{INTRODUCTION}

B-glucans are naturally occurring polysaccharides consisting of glucose residues with $B-1,3 \rightarrow B 1,4$ or/and $B-1,6 \rightarrow D$-glycosidic bonds with various degree of polymerization. They are major structural components of the cell walls of many organisms such as fungi, plants, mushrooms, bacteria, and yeasts. ß-glucans have been reported to possess anticancer, pro-inflammatory, and anti-fungal activities when administered to animals. Some reports have even indicated anti-parasitic effects. Stimulation of non-specific defense mechanisms has also been reported in fish (1-4). The terminology typically used to indicate any activation of immune mechanisms is either "priming," "immune induction" "immunostimulation" or "immunomodulation," explaining the outcome of a particular treatment (5). More recently the terminology has more or less shifted and is now called trained immunity, or better-trained innate immunity if the effects from the particular treatment induces non-specific/heterologous disease resistance, it is relatively long-lasting and it 
induce epigenetic changes $(5,6)$. In this perspective, we will discuss how in practical terms and based on prior knowledge one can introduce innate immune training in brood stock fish, and their offspring, and whether innate immune training by $ß$-glucans is a viable approach in larval aquaculture.

\section{TRAINED INNATE IMMUNITY: CONCEPT AND EXAMPLES}

Trained innate immunity can be explained by innate immune defense stimulation that may in turn confer increased nonspecific resistance to infection by homologous or heterologous pathogens. Examples have been retrieved from research on plants and invertebrates, where a certain kind of memory from previous insults exists (7). In vertebrate species, several approaches using ligands to pattern recognition receptors (e.g., ß-glucan, muramyl dipeptide, $\mathrm{CpG}$ containing oligodeoxynucleotides, flagellin) have suggested that priming of mice by some of these stimulants may facilitate protection against infection by heterologous pathogens (8). An illustrative example is where pretreatment of $B$-glucan coated microbeads fully protect mice against an otherwise lethal Escherichia coli challenge in mice (9). Other examples are the prophylactic effects from a B-glucan (laminaran) injection against Vibrio salmonicida infection in fish (10) and where Bacillus Calmette Guerin (BCG) vaccination induce T-cell independent non-specific disease protection against infections of e.g., Candida albicans and Schistosoma mansoni in mice $(11,12)$. Thus, the term trained innate immunity is a new wrapping of what has been observed and reported decades ago. However, a few more characteristics have since been added to the concept due to more research and the use of modern technologies. These are: $\mathrm{T}$ - and $\mathrm{B}$-cell independent process, epigenetic changes together with altered metabolic profile (13). The mechanisms behind priming or training are acknowledged to be functional (re)programming of cells (monocytes, macrophages, NK cells) induced by activation of particular pattern recognition receptors, mainly MAP kinase dependent intracellular signaling, and resulting epigenetic changes $(8,14)$. It should be noted that there exist other venues where cross-protection occurs. Poly-specific lymphocytes, the Mackaness reaction (chronic infection), and microbiota-mediated protection may all be venues to protective mechanisms, reviewed by Muraille (15). It is commonly acknowledged that B-cell produced antibodies, including natural antibodies, are not involved in trained innate immunity (16). Sea water is extremely rich in microbes (phages, viruses, bacteria), containing molecules that may induce immune activation or tolerance. The fish gut microbiome has been reported to consist of many species of the proteobacterial phylum (17). These are gram-negative bacteria with bacterial lipopolysaccharide (LPS) in their outer membrane, which is known to induce substantial immune activation. An attractive research question is why continuous exposure of high amounts of environmental LPS does not induce hyperactivation of the immune system. This issue may be dependent on the dose, where sensitization occurs by a low-dose LPS, whereas priming with high-dose LPS induces prolonged inhibition of inflammatory cytokine release-dependent on the mTOR (mammalian target of rapamycin) and AMPK (AMP-activated kinase) signaling axes. Such inhibition can be translated as LPS tolerance (8, 18, 19). mTOR is involved in anabolic processes during cell activation, whereas the latter is central in tissue homeostasis and tolerogenic responses. It is not yet clear whether $B$-glucans themselves induce tolerance that would be detrimental to their stimulating effects. Moreover, many fish species possess several splicing isoforms of e.g., PPRs where an activation of one of the spliced isoforms of a given pattern recognition receptor (12) might give another outcome (e.g., negative regulation) than expected (20-22).

\section{B-GLUCANS: NOT ALL ARE ALIKE}

Since there are high level of heterogeneities (and impurities) among different commercial preparations of $B$-glucans from various sources cautions must be made (23). One type of $B$ glucan from one species can be very different with respect to solubility in e.g., PBS/saline and gelling characteristics, compared to another $ß$-glucan preparation. Zymosan (Saccharomyces cerevisiae), the most widely applied and investigated $ß$-glucan, is composed of $\sim 50 \%$ B-glucan, $17 \%$ mannan, $14 \%$ protein, and other substances $(24,25)$. Zymosan (average $3 \mu \mathrm{m}$ particles) is extremely aqueous insoluble, but the particles can be dispersed in solutions. Other well-studied biologically active $B$ glucans includes laminarin, curdlan, lentinan, scleroglucan, and schizophyllan. In many cases their names are trivial describing their sources; Lentinan from Lentinula edodes, scleroglucan from Sclerotium sp., and schizophyllan from Schizophyllum commune (26). These microbial or fungal $ß$-glucans possess various degrees of polymerization that dictate, in some instances, a higher order of conformation-they are either linear and unbranched, or branched with single glucose residue-which in turns determines aqueous solubility, gelling characteristics, and often biological activities (27). Many $ß$-glucans have been reported to possess biological activities, such as induction of disease resistance, in both animals (vertebrates, invertebrates) and plants (4, 28-30).

\section{WHICH B-GLUCANS INDUCE TRAINED IMMUNITY?}

It is suggested that in order to induce trained innate immunity by ß-glucans, several different receptors must be engaged, such as Dectin-1, and dimeric TLR2/6 (31). The simultaneous binding of ß-glucan to two or more different receptors in clusters normally gives a higher response, compared to a single receptor. It is acknowledged that, among $ß$-glucans, particulate $ß$-glucans may be the optimal preparation to induce innate immune training, whereas low molecular weight $ß$-glucans (e.g., laminarin) do not favor a high response (32). 


\section{HIGH DIVERSITY OF INNATE RECEPTORS FOR INNATE TRAINING}

Teleost fish constitute a highly diverse group of animals, comprising of more than 23,000 different species. Twenty-one different Toll-like receptors (TLRs), together with additional splicing variants (subtypes/isotypes), have thus far been identified in teleost, reviewed by Chang et al. (22) and Nie et al. (33). The number of TLR variants far exceeds that found in mice and human (34). Furthermore, a recent analysis of the Atlantic cod genome and RNAseq analysis revealed that the cod TLR repertoire is extremely diversified, with 43 different TLRs ortologs and paralogs (35). Another example is that of the blue-spotted (Periophthalmodon schlosseri) and giant-fin (Periophthalmus magnuspinnatus) mudskipper genomes which contain 11 copies of TLR13 (36). Genome duplication events in fishes during evolution has been attributed to the diversity of TLRs, thus differences with respect to the number of TLR loci exist between mammalian species and many fish species (34). The number of TLRs added to other pattern recognition receptors (12) (including splice variants) such as different C-type lectin receptors, NOD-like (nucleotidebinding oligomerization domain-like) receptors (NLRs), RIG-1like receptors, and scavenger receptors (37), suggests that fish may very well be equipped with innate receptors that may likely be targets for innate immune training. Especially NLRs has been found to be highly expanded as shown in zebrafish, where nearly 400 NLR proteins are encoded in the zebrafish genome (38). The TLRs and NLRs outnumbers RIG-1-like receptors (39) and scavenger receptors (40) in fish, but future genomic analysis may reveal whether there are more copies of the two latter receptor families. The NLRs may likely be involved in gut responses to microbiota, as NOD1/2 are expressed on gut (zebrafish) epithelial cells (41).

One may strongly assume that trained innate immunity also exists in fish, but no definite proof exists-especially with regards to both epigenetic and metabolic changes together with the possibility of rewiring the trained state. Suggestions that trained innate immunity indeed is present in fish are based on experiments using B-glucans and other immunostimulants in vitro and in vivo, summarized by Petit and Wiegertjes (4) and Rojo-Cebreros et al. (42).

\section{TRAINED INNATE IMMUNITY IN BROOD STOCK FISH AND FISH LARVAL REARING}

Given that it is possible enhance the innate defense of fish through immune training-especially against pathogens-it opens up for several interesting approaches in fish larval rearing. Firstly, brood stock (female and male) fish may be stimulated with $\mathrm{PAMP}(\mathrm{s})$ at a low dose (16) inducing increased potential to, not only resist present pathogens, but to also transfer trained innate immunity to offspring (F1 generation). This is in line with a study by Beemelmanns and Roth that suggested the occurrence of maternal and paternal transfer of immune traits. In this study they found that pipefish (Syngnathus tyhple) offspring expression patterns of immune genes and epigenetic regulation is correlated to parental gene expression patterns (43). Intergenerational (F0F1) transfer of trained innate immunity has been reported for other animal species such as Artemia, oyster, red flour beetle, and humans (44-47). Interestingly transgenerational immune priming beyond $\mathrm{F} 1$ generation (F0F2) has also been observed in fish (S. typhle) (48).

Besides direct innate immune training of brood stock fish and transfer to F1 (and maybe F2) generations, molecules that are known to induce trained innate immunity may be maternally transferred and taken up by developing oocytes during vitellogenesis (49)-potentially increasing the innate defense of developing embryo/larvae-while the fish embryo or larvae is still in the eggs. The latter do not represent heritable trained traits, merely a direct innate immune stimulation of offspring. In summary, by administering immunostimulants (e.g., certain PAMPs) to brood stock fish one may obtain: (1) Direct maternal and paternal immunostimulation/training, (2) consequently inherited trained innate immunity, and (3) direct

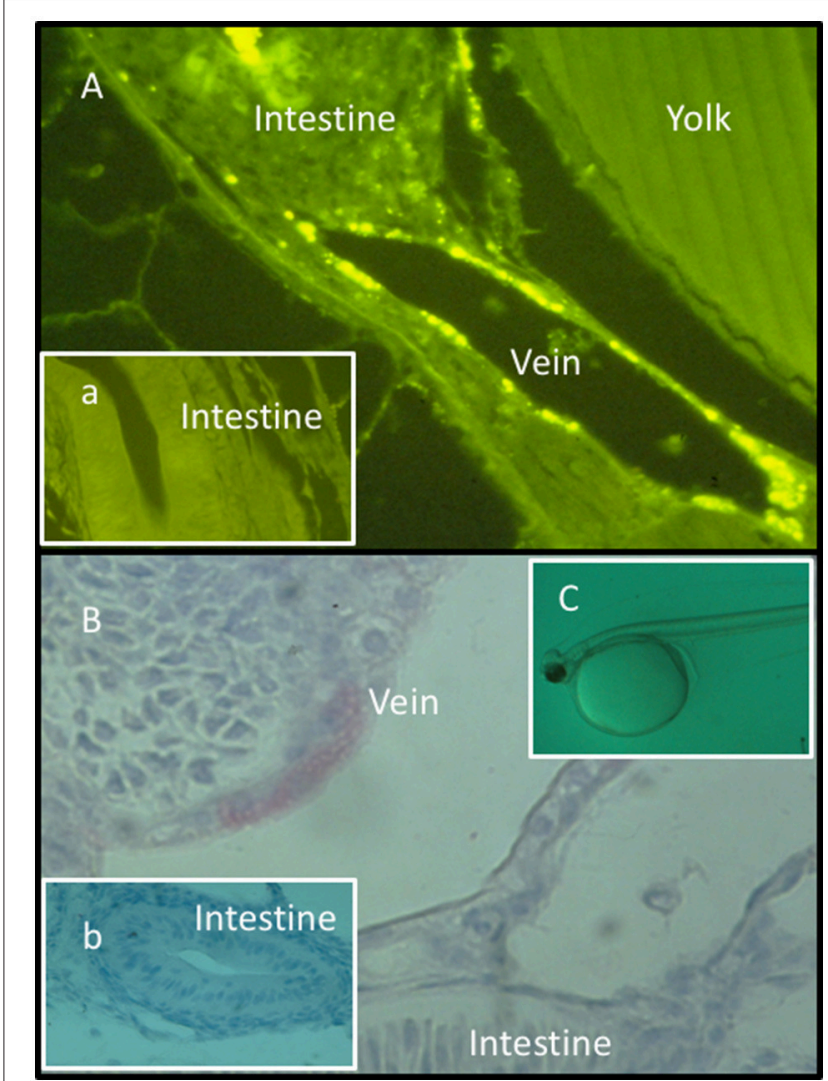

FIGURE 1 | Fluorescence (A, a) and light micrographs

(immunohistochemistry) $\mathbf{( B ,} \mathbf{b})$ of sections from Atlantic halibut yolk sac larvae (C) bath treated with FITC-labeled lipopolysaccharide (FITC-LPS). (a,b) Sections obtained from untreated larvae. FITC-LPS was found in endothelial cells in blood veins and in intestinal tissue documenting that yolk sac larvae cells have taken up FITC-LPS after bath treatment. Permission has been granted from Elsevier for $(\mathbf{A})$, where the rabbit anti $A$. salmonicida pabs was characterized and used (52). 
immune stimulation and training of developing embryo/larvae (inside egg chorion).

Secondly, substances expected to induce trained innate immunity may be administered directly to newly hatched fragile fish larvae or alevins (before first feeding) simply by bath treatment (50-54) (Figure 1).

Thirdly, first feeding represents a milestone during development of fish. After the yolk has more or less been utilized, the fish start feeding on algae, zooplankton, other prey, or simply pelleted formulated fish feed [for overview see Davies (53)] (55). For those fish species that feed on particulate feed, immunostimulants may simply be added to the formulated fish feed-for the purpose to induce innate immune training or immunostimulation $(42,50,53)$.

\section{POTENTIAL NEGATIVE EFFECTS OF EARLY TRAINED INNATE IMMUNITY}

If the initial stimulation, with purpose to induce innate immune training, otherwise induces hyperimmune responses in the mother/father or offspring it may give unwanted effects $(56,57)$ especially in vulnerable offspring that have not fully developed regulatory mechanisms. This issue, or related issues where brood stock fish has been (over)stimulated, has not been addressed yet. An important step will be to optimize the dose and duration for full innate immune training in brood stock fish. Early trained innate immunity may, at a later time point, interfere with subsequent vaccination regime, e.g., in commercial salmonid aquaculture. The fish vaccines often contain different inactivated bacteria emulsified in mineral oil, containing many substances

\section{REFERENCES}

1. Dalmo RA, Bogwald J. Beta-glucans as conductors of immune symphonies. Fish Shellfish Immun. (2008) 25:384-96. doi: 10.1016/j.fsi.2008.04.008

2. Meena DK, Das P, Kumar S, Mandal SC, Prusty AK, Singh SK, et al. Betaglucan: an ideal immunostimulant in aquaculture (a review). Fish Physiol Biochem. (2013) 39:431-57. doi: 10.1007/s10695-012-9710-5

3. Vetvicka V, Vannucci L, Sima P. The effects of beta - glucan on fish immunity. N Am J Med Sci. (2013) 5:580-8. doi: 10.4103/1947-2714.120792

4. Petit J, Wiegertjes GF. Long-lived effects of administering beta-glucans: indications for trained immunity in fish. Dev Comp Immunol. (2016) 64:93102. doi: 10.1016/j.dci.2016.03.003

5. Boraschi D, Italiani P. Innate immune memory: time for adopting a correct terminology. Front Immunol. (2018) 9:799. doi: 10.3389/fimmu.2018.00799

6. Netea MG, Quintin J, van der Meer JWM. Trained immunity: a memory for innate host defense. Cell Host Microbe (2011) 9:355-61. doi: 10.1016/j.chom.2011.04.006

7. Netea MG, van der Meer JWM. Trained immunity: an ancient way of remembering. Cell Host Microbe (2017) 21:297-300. doi: 10.1016/j.chom.2017.02.003

8. Ifrim DC, Quintin J, Joosten LAB, Jacobs C, Jansen T, Jacobs L, et al. Trained immunity or tolerance: opposing functional programs induced in human monocytes after engagement of various pattern recognition receptors. Clin Vaccine Immunol. (2014) 21:534-45. doi: 10.1128/CVI.00688-13

9. Seljelid R, Rasmussen LT, Larm O, Hoffman J. The protective effect of beta 13D-glucan-derivatized plastic beads against Escherichia coli infection in mice. Scand J Immunol. (1987) 25:55-60. doi: 10.1111/j.1365-3083.1987.tb01046.x

10. Dalmo RA, Martinsen B, Horsberg TE, Ramstad A, Syvertsen C, Seljelid R, et al. Prophylactic effect of beta(1,3)-D-glucan (laminaran) against experimental Aeromonas salmonicida and Vibrio salmonicida infections. J Fish Dis. (1998) 21:459-62. doi: 10.1046/j.1365-2761.1998.00120.x
(58) that potentially have effect on innate defense mechanisms. Would the trained characteristics in non-vaccinated individuals be wiped out/rewired or further potentiated? One should also address whether innate trained immunity affects (later) antibody response from vaccination, especially since there is an interplay between innate pattern recognition receptors and acquired immunity (59).

\section{CONCLUSION}

Training of innate immunity offers an interesting and attractive approach to increase disease resistance of brood stock fish, newly hatched fish larvae, and first feeding fish. Several TLR receptor ligands may be used to study innate training, assessed by modern technologies such as transcriptomics, epigenetics, proteomics, and metabolomics. In addition, in vivo pathogen challenge would be necessary to analyze whether a trained innate immunity has occurred or not.

\section{AUTHOR CONTRIBUTIONS}

All authors listed have made a substantial, direct and intellectual contribution to the work, and approved it for publication.

\section{FUNDING}

The work was supported by grants from the Research Council of Norway (grants 237315 and 239140), University of Tromsø (UIT The Arctic University of Norway Open Access publication Fund) and Tromsø Research Foundation.
11. van 't Wout JW, Poell R, van Furth R. The role of BCG/PPD-activated macrophages in resistance against systemic candidiasis in mice. Scand $J$ Immunol. (1992) 36:713-9. doi: 10.1111/j.1365-3083.1992.tb03132.x

12. Tribouley J, Tribouley-Duret J, Appriou M. [Effect of Bacillus Callmette Guerin (BCG) on the receptivity of nude mice to Schistosoma mansoni]. Influence du bacille de Calmette et Guerin (BCG) sur la receptivite de la Souris nude vis-a-vis de Schistosoma mansoni. C R Seances Soc Biol Fil. (1978) 172:902-4.

13. Arts RJW, Joosten LAB, Netea MG. The potential role of trained immunity in autoimmune and autoinflammatory disorders. Front Immunol. (2018) 9:298. doi: $10.3389 /$ fimmu. 2018.00298

14. Lau CM, Adams NM, Geary CD, Weizman OE, Rapp M, Pritykin Y, et al. Epigenetic control of innate and adaptive immune memory. Nat Immunol. (2018) 19:963-72. doi: 10.1038/s41590-018-0176-1

15. Muraille E. The unspecific side of acquired immunity against infectious disease: causes and consequences. Front Microbiol. (2015) 6:1525. doi: 10.3389/fmicb.2015.01525

16. Rusek P, Wala M, Druszczynska M, Fol M. Infectious agents as stimuli of trained innate immunity. Int J Mol Sci. (2018) 19:e456. doi: 10.3390/ijms19020456

17. Egerton S, Culloty S, Whooley J, Stanton C, Ross RP. The gut microbiota of marine fish. Front Microbiol. (2018) 9:873. doi: 10.3389/fmicb.2018.00873

18. Bauer M, Weis S, Netea MG, Wetzker R. Remembering pathogen dose: longterm adaptation in innate immunity. Trends Immunol. (2018) 39:438-45. doi: 10.1016/j.it.2018.04.001

19. Butcher SK, O'Carroll CE, Wells CA, Carmody RJ. Toll-like receptors drive specific patterns of tolerance and training on restimulation of macrophages. Front Immunol. (2018) 9:933. doi: 10.3389/fimmu.2018.00933

20. Lee FFY, Chuang HC, Chen NY, Nagarajan G, Chiou PP. Toll-like receptor 9 alternatively spliced isoform negatively regulates tlr9 signaling in teleost fish. PLoS ONE (2015) 10:e0126388. doi: 10.1371/journal.pone.0126388 
21. Candel S, Tyrkalska SD, Garcia-Moreno D, Meseguer J, Mulero V. Identification of evolutionarily conserved md1 splice variants that regulate innate immunity through differential induction of NF-?B. J Immunol. (2016) 197:1379-88. doi: 10.4049/jimmunol.1502052

22. Chang MX, Zhang J. Alternative Pre-mRNA splicing in mammals and teleost fish: a effective strategy for the regulation of immune responses against pathogen infection. Int J Mol Sci. (2017) 18:e1530. doi: 10.3390/ijms18071530

23. Camilli G, Tabouret G, Quintin J. The complexity of fungal beta-glucan in health and disease: effects on the mononuclear phagocyte system. Front Immunol. (2018) 9:673. doi: 10.3389/fimmu.2018.00673

24. Vetvicka V, Vetvickova J. Glucans and cancer: comparison of commercially available beta-glucans - Part IV. Anticancer Res. (2018) 38:1327-33. doi: 10.21873/anticanres. 12355

25. Bacon JSD, Farmer VC, Jones D, Taylor IF. Glucan components of cell wall of bakers yeast (Saccharomyces cerevisiae) considered in relation to its ultrastructure. Biochem J. (1969) 114:557-67. doi: 10.1042/bj1140557

26. Synytsya A, Novak M. Structural analysis of glucans. Ann Transl Med. (2014) 2:17. doi: 10.3978/j.issn.2305-5839.2014.02.07

27. Wang Q, Sheng XJ, Shi AM, Hu H, Yang Y, Liu L, et al. beta-Glucans: relationships between modification, conformation and functional activities. Molecules (2017) 22:e257. doi: 10.3390/molecules22020257

28. Fesel PH, Zuccaro A. beta-glucan: Crucial component of the fungal cell wall and elusive MAMP in plants. Fungal Genet Biol. (2016) 90:53-60. doi: 10.1016/j.fgb.2015.12.004

29. Soltanian S, Stuyven E, Cox E, Sorgeloos P, Bossier P. Beta-glucans as immunostimulant in vertebrates and invertebrates. Crit Rev Microbiol. (2009) 35:109-38. doi: 10.1080/10408410902753746

30. Bashir KMI, Choi J-S. Clinical and physiological perspectives of betaglucans: the past, present, and future. Int J Mol Sci. (2017) 18:e1906. doi: 10.3390/ijms18091906

31. Batbayar S, Lee DH, Kim HW. Immunomodulation of fungal beta-glucan in host defense signaling by dectin-1. Biomol Ther. (2012) 20:433-45. doi: 10.4062/biomolther.2012.20.5.433

32. Goodridge HS, Reyes CN, Becker CA, Katsumoto TR, Ma J, Wolf AJ, et al. Activation of the innate immune receptor Dectin-1 upon formation of a 'phagocytic synapse'. Nature (2011) 472:471-5. doi: 10.1038/nature10071

33. Nie L, Cai SY, Shao JZ, Chen J. Toll-Like receptors, associated biological roles, and signaling networks in non-mammals. Front Immunol. (2018) 9:1523. doi: $10.3389 /$ fimmu.2018.01523

34. Palti Y. Toll-like receptors in bony fish: from genomics to function. Dev Comp Immunol. (2011) 35:1263-72. doi: 10.1016/j.dci.2011.03.006

35. Solbakken MH, Torresen OK, Nederbragt AJ, Seppola M, Gregers TF, Jakobsen KS, et al. Evolutionary redesign of the Atlantic cod (Gadus morhua L.) Toll-like receptor repertoire by gene losses and expansions. Sci Rep. (2016) 6:25211. doi: 10.1038/srep25211

36. You XX, Bian C, Zan QJ, Xu X, Liu X, Chen JM, et al. Mudskipper genomes provide insights into the terrestrial adaptation of amphibious fishes. Nat Commun. (2014) 5:5594. doi: 10.1038/ncomms6594

37. Brubaker SW, Bonham KS, Zanoni I, Kagan JC. Innate immune pattern recognition: a cell biological perspective. Ann Rev Immunol. (2015) 33:257-90. doi: 10.1146/annurev-immunol-032414-112240

38. Howe K, Schiffer PH, Zielinski J, Wiehe T, Laird GK, Marioni JC, et al. Structure and evolutionary history of a large family of NLR proteins in the zebrafish. Open Biol. (2016) 6:160009. doi: 10.1098/rsob.160009

39. Chen SN, Zou PF, Nie P. Retinoic acid-inducible gene I (RIG-I)-like receptors (RLRs) in fish: current knowledge and future perspectives. Immunology (2017) 151:16-25. doi: 10.1111/imm.12714

40. Yap NVL, Whelan FJ, Bowdish DME, Golding GB. The evolution of the scavenger receptor cysteine-rich domain of the class A scavenger receptors. Front Immunol. (2015) 6:342. doi: 10.3389/fimmu.2015.00342

41. Oehlers SH, Flores MV, Hall CJ, Swift S, Crosier KE, Crosier PS. The inflammatory bowel disease (IBD) susceptibility genes NOD1 and NOD2 have conserved anti-bacterial roles in zebrafish. Dis Model Mech. (2011) 4:832-41. doi: $10.1242 / \mathrm{dmm} .006122$

42. Rojo-Cebreros AH, Ibarra-Castro L, Martinez-Brown JM. Immunostimulation and trained immunity in marine fish larvae. Fish Shellfish Immun. (2018) 80:15-21. doi: 10.1016/j.fsi.2018.05.044
43. Beemelmanns A, Roth O. Biparental immune priming in the pipefish Syngnathus typhle. Zoology (2016) 119:262-72. doi: 10.1016/j.zool.2016. 06.002

44. Roth O, Joop G, Eggert H, Hilbert J, Daniel J, Schmid-Hempel P, et al. Paternally derived immune priming for offspring in the red flour beetle, Tribolium castaneum. J Anim Ecol. (2010) 79:403-13. doi: 10.1111/j.1365-2656.2009.01617.x

45. Hong M, Sandalova E, Low D, Gehring AJ, Fieni S, Amadei B, et al. Trained immunity in newborn infants of HBV-infected mothers. Nat Commun. (2015) 6:6588. doi: $10.1038 /$ ncomms7588

46. Norouzitallab P, Baruah K, Biswas P, Vanrompay D, Bossier P. Probing the phenomenon of trained immunity in invertebrates during a transgenerational study, using brine shrimp Artemia as a model system. Sci Rep. (2016) 6:21166. doi: $10.1038 /$ srep21166

47. Green TJ, Helbig K, Speck P, Raftos DA. Primed for success: oyster parents treated with poly(I:C) produce offspring with enhanced protection against Ostreid herpesvirus type I infection. Mol Immunol. (2016) 78:113-20. doi: 10.1016/j.molimm.2016.09.002

48. Beemelmanns A, Roth O. Grandparental immune priming in the pipefish Syngnathus typhle. BMC Evol Biol. (2017) 17:44. doi: 10.1186/s12862-017-0885-3

49. Hara A, Hiramatsu N, Fujita T. Vitellogenesis and choriogenesis in fishes. Fish Sci. (2016) 82:187-202. doi: 10.1007/s12562-015-0957-5

50. Bricknell I, Dalmo RA. The use of immunostimulants in fish larval aquaculture. Fish Shellfish Immun. (2005) 19:457-72. doi: 10.1016/j.fsi.2005.03.008

51. Zhang ZB, Swain T, Bogwald J, Dalmo RA, Kumari J. Bath immunostimulation of rainbow trout (Oncorhynchus mykiss) fry induces enhancement of inflammatory cytokine transcripts, while repeated bath induce no changes. Fish Shellfish Immun. (2009) 26:677-84. doi: 10.1016/j.fsi.2009.02.014

52. Dalmo RA, Kjerstad AA, Arnesen SM, Tobias PS, Bogwald J. Bath exposure of Atlantic halibut (Hippoglossus hippoglossus L.) yolk sac larvae to bacterial lipopolysaccharide (LPS): absorption and distribution of the LPS and effect on fish survival. Fish Shellfish Immun. (2000) 10:107-28. doi: 10.1006/fsim.1999.0231

53. Magnadottir B, Gudmundsdottir BK, Lange S, Steinarsson A, Oddgeirsson M, Bowden T, et al. Immunostimulation of larvae and juveniles of cod, Gadus morhua L. J Fish Dis. (2006) 29:147-55. doi: 10.1111/j.1365-2761.2006.00701.x

54. Oyarbide U, Rainieri S, Pardo MA. Zebrafish (Danio rerio) larvae as a system to test the efficacy of polysaccharides as immunostimulants. Zebrafish (2012) 9:74-84. doi: 10.1089/zeb.2011.0724

55. Davis DA. Feed and Feeding Practices in Aquaculture. Boston, MA: Elsevier (2015).

56. Levy O, Wynn JL. A prime time for trained immunity: innate immune memory in newborns and infants. Neonatology (2014) 105:136-41. doi: $10.1159 / 000356035$

57. Morelli SS, Mandal M, Goldsmith LT, Kashani BN, Ponzio NM. The maternal immune system during pregnancy and its influence on fetal development. Res Rep Biol. (2015) 6:171-89. doi: 10.2147/RRB.S80652

58. Savva A, Roger T. Targeting toll-like receptors: promising therapeutic strategies for the management of sepsis-associated pathology and infectious diseases. Front Immunol. (2013) 4:387. doi: 10.3389/fimmu.2013.00387

59. Akira S, Takeda K, Kaisho T. Toll-like receptors: critical proteins linking innate and acquired immunity. Nat Immunol. (2001) 2:675-80. doi: $10.1038 / 90609$

Conflict of Interest Statement: The authors declare that the research was conducted in the absence of any commercial or financial relationships that could be construed as a potential conflict of interest.

Copyright (c) 2019 Zhang, Chi and Dalmo. This is an open-access article distributed under the terms of the Creative Commons Attribution License (CC BY). The use distribution or reproduction in other forums is permitted, provided the original author(s) and the copyright owner(s) are credited and that the original publication in this journal is cited, in accordance with accepted academic practice. No use, distribution or reproduction is permitted which does not comply with these terms. 